This item was submitted to Loughborough's Research Repository by the author.

Items in Figshare are protected by copyright, with all rights reserved, unless otherwise indicated.

\title{
Researching sport management
}

PLEASE CITE THE PUBLISHED VERSION

https://www.routledge.com/products/9780415570299

\section{PUBLISHER}

(C) Taylor \& Francis (Routledge)

\section{VERSION}

SMUR (Submitted Manuscript Under Review)

\section{PUBLISHER STATEMENT}

This work is made available according to the conditions of the Creative Commons Attribution-NonCommercialNoDerivatives 4.0 International (CC BY-NC-ND 4.0) licence. Full details of this licence are available at: https://creativecommons.org/licenses/by-nc-nd/4.0/

\section{LICENCE}

CC BY-NC-ND 4.0

\section{REPOSITORY RECORD}

Edwards, Allan, James Skinner, and Wayne Usher. 2019. "Researching Sport Management". figshare. https://hdl.handle.net/2134/20368. 


\section{Researching sport management}

Allan Edwards, James Skinner and Wayne Usher, Griffith University, Gold Coast, Australia

\section{TOPICS}

Sport management research • Quantitative research/ Qualitative research

- Basic research - Applied research

\section{OBJECTIVES}

At the end of this chapter you should be able to:

- Explain the evolution of sport management research;

- Make a clear distinction between qualitative, quantitative, and mixed methods approaches to sport management;

- Understand the difference between basic and applied research;

- Explain the research process and how it can be applied to sport management research.

\section{KEY TERMS}

Applied research - a type of research that has direct value to practitioners but in which the researcher has limited control over the research setting.

Basic research - a type of research that may have limited direct application but in which the researcher has careful control of the conditions.

Paradigm - is a set of propositions that explain how the world is perceived; it contains a worldview, a way of breaking down the complexity of the real world, informing researchers and social scientists in general what is important, what is legitimate, and what is reasonable. 
Qualitative research - research that seeks to provide an understanding of the human condition and which utilizes an interpretive approach to data analysis.

Quantitative research - the collection and analysis of data that can generally be expressed in a numeric format.

\section{OVERVIEW}

In this chapter we will discuss the importance of sport management research as well as the different research methods currently employed by sport management researchers. By looking at the current state of research in sport management, we can examine what the future of sport management research may look like - how new and innovative ways of conceptualizing and investigating issues of importance to sport management researchers and practitioners can offer potential solutions to emerging problems in the world of sport management research.

There is not just one way to do research. Some people do undertake research from this perspective whilst others are critical of the methods used by different researchers. Instead research should be disciplined inquiry, not a set of specific procedures.

The two main types of research are basic and applied. Basic research deals primarily with theoretical problems, and these results are not intended to have immediate application. Applied research, on the other hand, strives to answer questions that have direct value to the practitioner. Sport management research is not only important for the researcher. By undertaking relevant research that asks and seeks answers to important questions and issues that are of direct relevance to practitioners, we are developing not only proficient researchers but proficient and informed consumers of research.

\section{CASE STUDY: USING A MIXED METHODS APPROACH}

Estella (Terry) Engelberg completed a study entitled 'The Commitment of Volunteers in Junior Sport Organisations: A Mixed Methods Study'. The purpose of this study was to examine the dimensionality and targets of the commitment of volunteers in junior sport organizations, and the links between commitment and behavioural outcomes, specifically one's intention to stand down from a volunteer role, intention to cease volunteering for the club or centre, and self-assessed performance. Terry utilized a sequential explanatory mixed methods design consisting of both quantitative and qualitative phases. The quantitative phase studies assessment commitment to three organizational targets: the organization, the team of volunteers, and the volunteer role. The qualitative study explored and explained the findings of the quantitative phase in more depth and allowed the volunteers to 'use their own voice' in the discussion. The results of the studies indicated that commitment is a multidimensional construct that can be applied to various organizational targets, and that there are differences in commitment amongst volunteer subgroups, such as committee members and volunteers in other roles, volunteers with children, and volunteers without children.

Source: Edwards \& Skinner, 2009, p. 7

428 


\section{WHAT IS SPORT MANAGEMENT RESEARCH?}

At its basic level, research is a way of investigating problems with the aim of finding solutions to those problems, or at least raising questions and issues that future researchers will investigate. This is true of sport management research as well. The sport management researcher devises questions that relate to specific problems or issues in the field, and then devises methods by which these problems or issues can be answered or explained. Sport management research involves systematic exploration, guided by well-constructed questions, and producing new information or reassessing old information. Creswell (2008) defines research as 'a process of steps used to collect and analyse information to increase our understanding of a topic or issue' (p. 3). Sport management researchers spend a great deal of time evaluating other people's research, deciding what the strengths and weaknesses are in each case, and hoping to apply their conclusions to their own reading and to the procedures they follow in their research. In this chapter, the issue of a sport management researcher's own value systems is discussed as these value systems will inevitably come into play when a researcher uses qualitative research methods. Sport management researchers therefore need to look carefully at the claims of others, judging for themselves whether or not those claims are convincing. To do that, they need to understand the process by which other researchers have come to their conclusions, and this means understanding both their methodologies and the intellectual frameworks within which they have operated.

\section{Origins of sport management research}

Edwards and Skinner (2009) discuss the evolution of sport management as an independent discipline throughout the 1980s and 1990s. Costa (2005) suggests that the discipline of sport management was finally defined following the founding of the North American Society for Sport Management (NASSM) in 1985, and the subsequent formation of the European Association of Sport Management (EASM) in 1993 and, in turn, the Sport Management Association of Australia and New Zealand (SMAANZ) in 1995.

The mere recognition of sport management as an independent discipline, however, would be insufficient to sustain it in the academic world. Pitts (2001) suggests that 'a field of study cannot exist without a body of knowledge and literature' (p. 2) that has been formed through the process of research. Research in sport management has historically been dominated by positivistic, quantitative methodologies (Amis \& Silk, 2005); however, more recently sport management researchers (e.g. Chalip, 2006; Edwards \& Skinner, 2009; Frisby, 2005) have acknowledged the need to consider and embrace alternative worldviews and eclectic methodological approaches to examine questions about the social world (Quatman, 2006).

Quatman (2006) indicates that the 2005 special issue in the Journal of Sport Management reflected on the "Constrained idea space (i.e., content and diversity of knowledge circulating) in the field and focused on "expanding the horizons" of sport management research through critical and innovative approaches' (p. 2). Quatman goes on to suggest that the core theme of the special edition clearly suggests that there is a need to move beyond current research practices and embrace socially inclusive approaches to understanding the lived experiences of sport managers in order to promote a more inclusive culture for the generation of knowledge in the field.

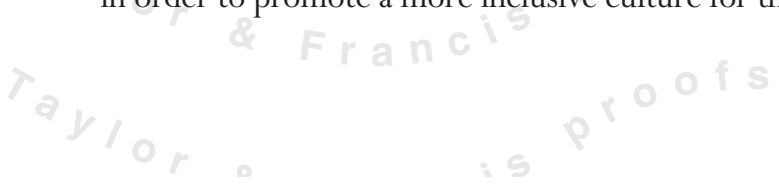

429 


\section{Why do sport management research?}

Research and reflection are essential in any discipline if that discipline is to grow in a positive and beneficial way. Thomas, Nelson, and Silverman (2005) assert that one 'of the primary distinctions between a discipline or profession and trade is that the trade deals only with how to deal with something, whereas the discipline or profession concerns itself not only with how but also with why something should be done in a certain manner (and why it should even be done)' (p. 6). Thomas et al. further go on to discuss some of the problems associated with research and its applicability to practitioners and professionals in the field, and these can be directly related to sport management research and the sport management practitioner. In particular they discuss the language and jargon of research which can be at times too technical, too unfamiliar, and, dare we say, too 'academic'. Additionally, practitioners do not see the relevance of the work they are actually undertaking. These are all concerns that the sport management researcher should heed before embarking on their research project. They should ask some important questions of themselves - Is this topic relevant? Who will benefit from this research? Perhaps if the answers to these questions are that the topic is of relevance only to the researcher, and the researcher themselves is the primary beneficiary of the research outcome, then serious consideration should be given before proceeding down this particular path.

Sport management research can add important information to the discipline's knowledge base - and such information, where relevant, can be drawn on by other researchers, practitioners, policy makers, and even other stakeholders such as club members, athletes, fans, existing and potential sponsors, advertisers, marketers, and any other interested member of the general public. For the researcher, a particular research study may be on a topic or issue previously ignored, or perhaps on a 'new' topic which has never been considered before. The research may also build on previous research studies - providing results to confirm the previous study, or even to question these. This is true of any academic discipline, and sport management is no exception. A research report might provide a study that has not been conducted and thereby fill a void in existing knowledge. It can also provide additional results to confirm or disconfirm results of prior studies. It can help add to the literature about practices that work or advance better practices for the sport management professional.

Research can also suggest improvements for practice, giving sport management practitioners new ideas with which to develop new processes and procedures and ultimately to become better at what they do. It also offers sport management practitioners new ideas to consider in their profession. It also helps practitioners evaluate approaches that they hope will work in their own management settings. At a broader level, research helps the sport management practitioner build connections with other practitioners who may be trying out similar ideas in different locations.

Research also creates conversations about important issues when policy makers debate issues that directly impact on sport managers, for example sport policy relating to drugs in sport. Research can help the policy makers weigh various perspectives. When the policy makers read research on issues, they are informed about current debates and stances taken by other public officials. To be useful, the research needs to have clear results, be summarized concisely, and include data-based evidence.

430 


\section{TYPES OF SPORT MANAGEMENT RESEARCH}

The two main types of research are basic research and applied research. These are, in effect, the 'extremes' of the research continuum - with Basic Research being at one end and applied research being at the other, as their methods and applicability to the sport management practitioner are so diverse. In the field of sport management, research is generally not only basic or applied, but often a combination of both.

Basic research is theoretical in nature, and deals with theoretical problems. It looks to try and make sense of the world and the way in which it operates. In general the research takes place in a controlled setting such as a laboratory, but for the sport manager this could be an interview room or any other venue where the researcher can control the conditions under which the research takes place. In this situation the results of research may have little direct application for the practitioner. The research may yield important data for the researcher; however, in the form in which the research is obtained and the types of data collected, it is unlikely to be of direct relevance to a sport management setting.

Applied research, on the other hand, takes place in the real world, or real-world settings such as the sporting organization, and therefore, if undertaken well, can produce results that are relevant to the sport management practitioner and can be implemented within the sporting organization to improve practice.

Most sport management research is neither purely applied nor purely basic but incorporates some aspects of both.

The sport management research process is outlined in Figure 24.1.

\section{The research process}

The first step to conducting sport management research is to identify the problem. Once the problem has been identified, reading and thinking about relevant theories and concepts, as well as a careful search of the literature for relevant findings, leads to the specification of hypotheses or questions. Operational definitions are needed in a research study so that the reader knows what the researcher means when they use/certain terms. Operational definitions describe observable phenomena that enable the researcher to examine empirically whether the predictions can be supported. The study is designed, and the methods are made operational. The data are then collected and analysed, and the findings identified. Finally the results are related back to the original hypotheses or questions and discussed in relation to theories, concepts, and previous research findings.

\section{The research topic}

The researcher begins a study by identifying a topic to study - this may be an issue or problem in the sport management area that needs to be resolved. This may be a high-profile issue recently identified in the media, or an issue around which little or no research has previously been conducted but which is of concern to sport managers. Once an issue is identified, the researcher will develop a justification for studying it, and suggest the importance of the study.

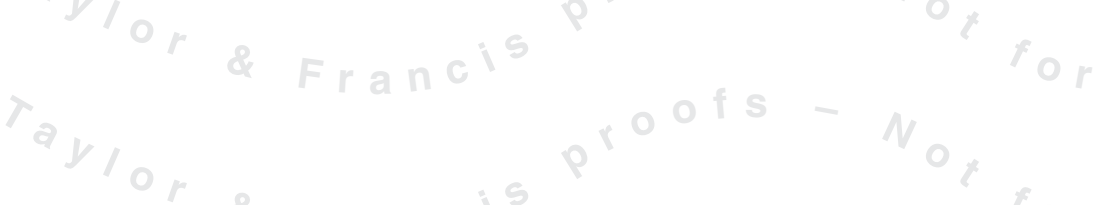




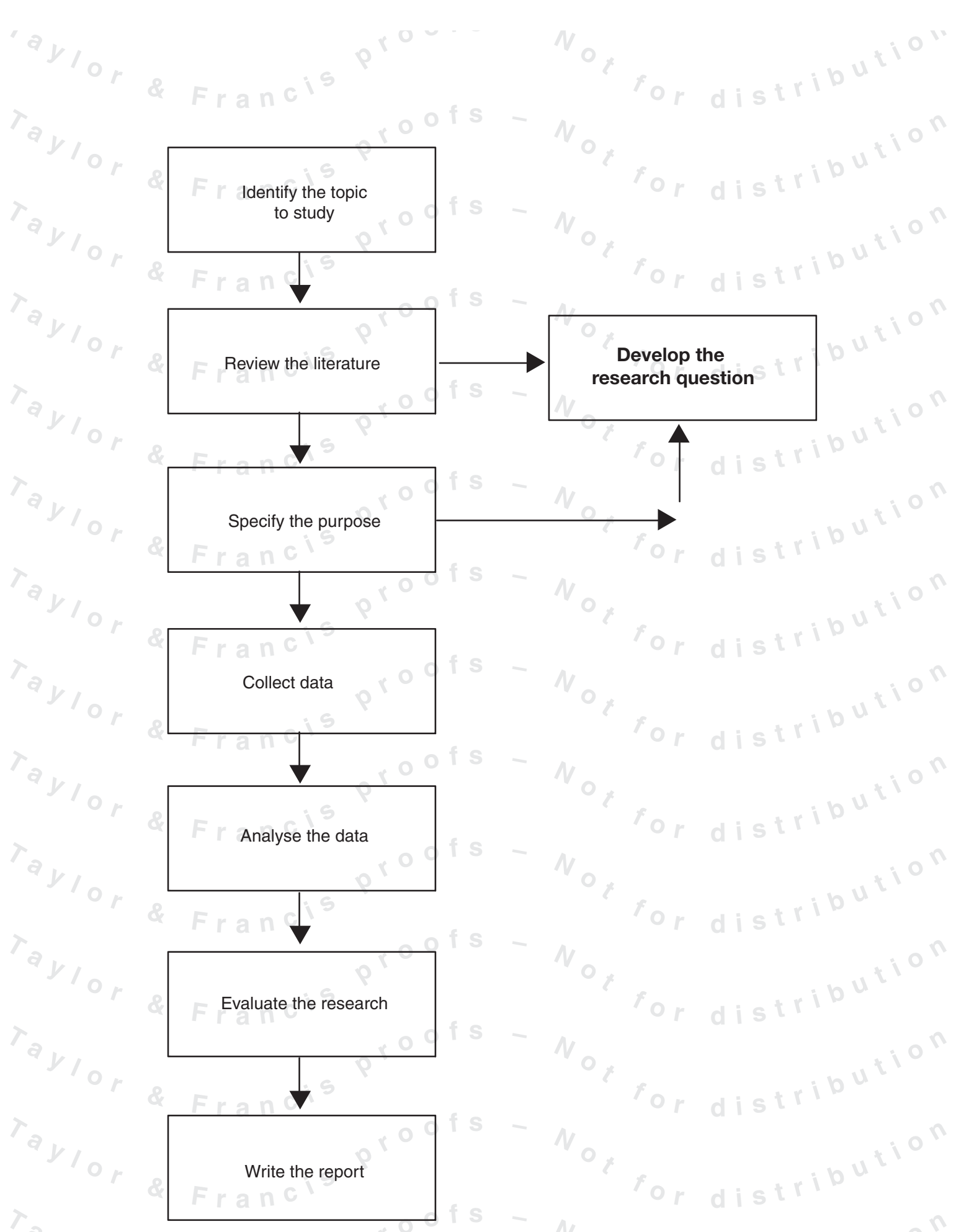

Figure 24.1 The sport management research process

432 


\section{Reviewing the literature}

Once a topic or problem has been identified, the researcher needs to know who has already studied and reported in this area. This is important because your study should build on existing knowledge and add to the bank of findings on a topic - not merely replicate existing studies.

Reviewing the literature means locating summaries, books, journals, publications, websites etc. on a topic. The researcher then selects which literature to include and summarizes them in a written report.

\section{Specifying a purpose for research}

This is where the sport management researcher specifies the overall objective or intent of the research. This is an extremely important section in the research study as it not only introduces the whole study, but lets the reader know what procedures will be used to collect data, and indicates the types of results you hope to find.

\section{Develop the research question}

Having decided on a topic, reviewed the literature, and defined the purpose of the research, the sport management researcher will develop a specific set of research questions that the research to be conducted will seek to answer or explain. These research questions will build on the purpose statement developed in the previous section.

\section{Collecting data}

Having established the parameters of the research and the research questions, the next step in the research process is actually to collect data. It is important that the data collected is accurate so that the hypotheses and answers generated by the research are valid. There are various methods of collecting data dependent on the theoretical model followed by the researcher. The major differences in data collection between quantitative, qualitative, or mixed methods approaches are discussed in more detail later in this chapter.

\section{Analysing the data}

Analysing the data involves drawing conclusions about the information collected. The results are often depicted in tables or figures in the case of quantitative data, with a discussion in words that aims to provide answers to the research questions. These will be reported in sections of a research report usually entitled Results, Findings, or Discussions, depending on whether the researcher has approached the research from a quantitative or qualitative methodology.

\section{Reporting and evaluating the research}

After conducting the research, one must develop a written report. Reporting research means deciding on the audience for the research, structuring the report in a format acceptable to that 
audience, and then writing the report in a manner that is sensitive to all readers. The audience for a sport management research report will range from academics actively researching in the area, to practitioners such as club and team managers, through to stakeholders in the government and private sector, as well as members of the general public who are actively interested in issues that affect their favourite team or sport.

\section{ETHICAL CONSIDERATIONS}

In all steps of the research process the sport management researcher needs to engage in ethical practices. At its most basic level this can consist of respecting the rights of participants, the research site itself, through to reporting the research fully and honestly. The importance of research ethics extends beyond this moral imperative to operate legally and ethically. Compliance with ethical standards can be a condition on which a researcher receives funding as well as a condition of publication in many journals. Access to certain research sites - sport schools, for example - can also be restricted and require high levels of compliance with ethical standards. Of major importance to sport management researchers is the perception and confidence of potential research participants in the ethical integrity of the research, which can help to ensure that these potential research participants are more likely to take part in the research study.

\section{Respecting the rights of participants}

Professional associations generally have a set of ethical standards by which researchers should abide. Students of sport management research should review the ethical standard requirements of their tertiary institution as a guide prior to commencing any research.

The sport management researcher needs to adhere to a basic concept - that participants in any study have certain rights, the most fundamental of which is not to be harmed in any way, whether it is physically, mentally, or emotionally. Participants also have the right to know the purpose and aims of the study prior to agreeing to participate, as well as any possible or likely consequences of participation - otherwise known as 'informed consent' (or assent if the subjects are minors). At any stage participants can refuse to engage with the research and can withdraw from the study at any time. The concept of privacy and anonymity is also extremely important and must be adhered to. This involves not only the identity of participants but also of the information provided.

\section{Respecting the integrity of the research site}

Before commencing research at a site, be it a sports club or sporting venue etc., the researcher should gain permission and aim to disturb the site as little as possible. This ensures not only the validity of the data collected but also that the research site will be more likely to agree in the future to participate in research studies.

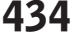




\section{Reporting research fully and honestly}

Information and data collected should be reported honestly, without changing or altering the findings to satisfy either the research questions or interest groups. There are times when the findings do not support the initial aims of the research question, and in some instances these can be viewed as exciting new research opportunities.

\section{Ethical context}

The sport management researcher should be reflecting on ethical considerations throughout the research process. There may be times when the sport management researcher faces difficult choices in relation to the conduct of the research and needs to weigh up the benefits of the research against any possible harm caused to participants in the study or the research site. Adhering to a system of research ethics will serve to guide the research in making those correct moral choices that will benefit both the participants in the study and the research study itself.

\section{APPROACHES TO SPORT MANAGEMENT RESEARCH}

The sport management researcher can approach their study in different ways or methods through a quantitative study, a qualitative study, or a combination of the two. The approach or method chosen is often driven by the type of problem being researched.

\section{Research paradigms}

Edwards and Skinner (2009) believe that most sport management researchers have an intellectual framework that governs the way they perceive the world and their own place within it, even if they are unable to articulate just what that framework is. This paradigm or framework shapes research from the beginning to the end, because it provides the structure within which choices (including the initial choice of a research subject) are made. This framework comes partly from the institutional setting within which research takes place - the position taken by employers or those who commissioned the research, or by supervisors, by the department within which researchers work, and by the university/college which employs them. Part of it will come from the personal position of the sport management researcher, which may have been shaped by their biography of experiences as well as their previous education, political and religious beliefs, gender, sexual preference, and race and/or class affiliations.

Frisby (2005) argues that if researchers are to understand all aspects of sport management then research needs to be conducted from 'multiple paradigms' (p. 2). Further, she says that the paradigms a researcher operates from 'shape the questions we ask, the methods we use, and the degree to which our findings will have an impact on society' (p. 2).

There is no single paradigm, and/or methodology, that meets the needs of all sport management researchers and all research questions, because the field of sport management research is diverse, complex, and evolving. The sport management researcher will adopt the methodology most appropriate for the research being conducted.
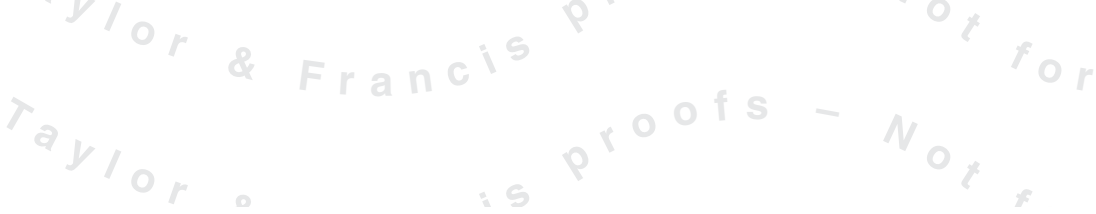


\section{TYPES OF SPORT MANAGEMENT RESEARCH METHODOLOGIES}

There is no one best research approach. The sport management researcher will determine which approach will be most effective for the resolution of the research question, and is often determined by the nature of the question or topic being investigated. The research methodology chosen will generally be influenced by the philosophical beliefs of the researcher as well as the resources available to conduct the research - including available participants and the research site. Undertaking research from a quantitative or qualitative perspective affects the approach to the research process itself.

\section{Quantitative research}

Some researchers suggest (Amis \& Silk, 2005; Cunningham \& Mahoney, 2004; Cuskelly \& Boag, 2001; Fink et al., 2003; Murray \& Howat, 2002; Quatman, 2006; Shilbury, 2001; Skinner \& Edwards, 2005) that quantitative approaches to sport management research have historically dominated the discipline. Quantitative research is a type of research in which the researcher decides what to study, asks specific, narrow questions, collects quantifiable data from participants, analyses these numbers using statistics, and conducts the inquiry in an unbiased, objective manner. Creswell (2008, p. 48) sees three main features of quantitative research that are prevalent today:

- Collecting and analysing information in a numeric form;

- Collecting scores and then using them to measure the performance or attributes of individuals and organizations;

- Procedures and processes by which groups are compared or which factors common to individuals or groups are related through experiments, surveys, correlation studies, and other methods.

\section{Identifying the research problem}

The researcher will look at trends or variables whose relationship can be defined in a quantifiable manner. For example, variables such as gender or age, and attitudes towards a specific type of behaviour such as illicit drug use in sport or bad off-field behaviour, could be studied to determine whether there is a relationship between the two and whether one variable influences another.

\section{Reviewing the literature}

In quantitative research the literature justifies the need for the study and suggests potential purposes and research questions. Within the literature the researcher will identify key variables, relations, and trends, and use these to provide direction for the research questions or hypotheses. For example, a literature review on drug use in a particular sport may show little in the way of trends or reported incidences in that particular sport; however, the literature may reveal useful data in relation to increasing trends in related sports as well as changing trends in public perceptions and tolerances for such behaviours.

436 


\section{Specifying a purpose for research}

In quantitative research, the purpose statement, research questions, and hypotheses tend to be specific and narrow and seek measurable, observable data on variables. The major statements and questions of direction in a study - the purpose statement, the research questions, and the hypotheses - are specific and narrow because one identifies only a few variables to study. From the study of these variables, one may obtain measures or assessments on an instrument or record scores on a scale from observations.

\section{Collecting data}

In quantitative research, the data collection tends to consist of collecting data using instruments with preset questions and responses, gathering quantifiable (numeric) data and collecting information from a large number of individuals. An instrument is a tool for measuring, observing, or documenting quantitative data. It contains specific questions and response possibilities that one establishes or develops in advance of the study. Examples of instruments are survey questionnaires, standardized tests, and checklists. The instruments are administered to participants and data is collected in the form of numbers. The intent of this process is to apply the results from a small number of people to a large number. The larger the number of individuals studied, the stronger the case for applying the results to a large number of people. For example, a survey sent to 500 parents of teenage football players from one club should provide a significant amount of data from which to extrapolate relevant information.

\section{Analysing and interpreting data}

In quantitative research the data analysis tends to consist of statistical analysis. Statistical analysis consists of breaking down the data into parts to answer the research questions. Statistical procedures such as comparing groups or relating scores for individuals provide information to address the research questions or hypotheses. These results are then interpreted in light of initial predictions or prior studies. Examples of data collected by the sport management researcher that could be analysed statistically include attendance figures at different sporting events (including a more detailed demographic analysis), club membership figures, and sporting participation rates.

\section{Reporting and evaluating research}

In quantitative research the researcher aims to take an objective and unbiased approach, ensuring that their own biases and values system do not influence the results. The format for a study follows a standard pattern of introduction, literature review, methods, results, and discussion. The research is also reported without reference to the researcher or their personal reaction to the results achieved.

Clearly there are many studies in which the sport management researcher will obtain useful and valuable data through the use of quantitative methods. Analysis of athlete performance across a number of events, a demographic analysis of attendance figures at sporting

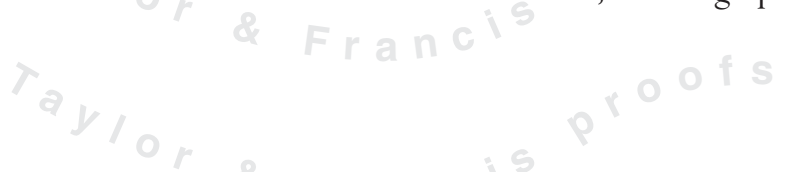


events, and even the analysis of sport merchandise consumption can provide valuable data to practitioners which can be used to shape and develop training regimes, develop marketing strategies, and address other specific areas of concern.

\section{Qualitative methods}

Qualitative research presents an alternative to the traditional form of quantitative research. Qualitative research has been constantly evolving since the late 1800 s, with the development of naturalistic inquiry or constructivism to emphasize the importance of participants' views, to take into account the setting or context in which the participants expressed those views, and look at the meanings that people assign to different issues. During the 1980 s and 1990s, types of qualitative research design emerged, including case studies, grounded theory research, and narrative inquiry, along with the emergence of qualitative computer software programs for data analysis.

In the 1990s and 2000s, researchers have seen the emergence of participatory and advocacy practices in qualitative research, themes which express concern for the needs of individuals in lower social classes, racial groups, and women. These themes called for researchers to report in their studies their own personal biases, values, and assumptions. It cast research into politics in which it considered the rights of women, gays, lesbians, racial groups, and different classes in our society, and honoured different viewpoints during both the writing and the reading of qualitative reports. It also spoke about qualitative data collection procedures in which inquirers were sensitive to participants, actively collaborated with them (rather than studying them), and respected the dignity of each individual who offered data for research.

Creswell (2008, p. 51) sees the current characteristics of qualitative research as:

- A recognition by researchers that they need to listen to the views of research participants;

- A recognition that researchers need to ask general, open questions and collect data in those places where people live and work;

- A recognition that research can advocate for change and better the lives of individuals.

\section{Identifying the research problem}

Qualitative research tends to address research problems where little is known about the problem and the researcher is looking to achieve a detailed understanding of a central or specific phenomenon. The literature may have provided little information about the area of study, and the researcher will seek to learn more from participants. The research problem may be an issue that has been presented in the media as being of concern to the public, such as (again) the use of illicit drugs in sport, and sport management research may seek to devise a study that will look at community attitudes towards this.

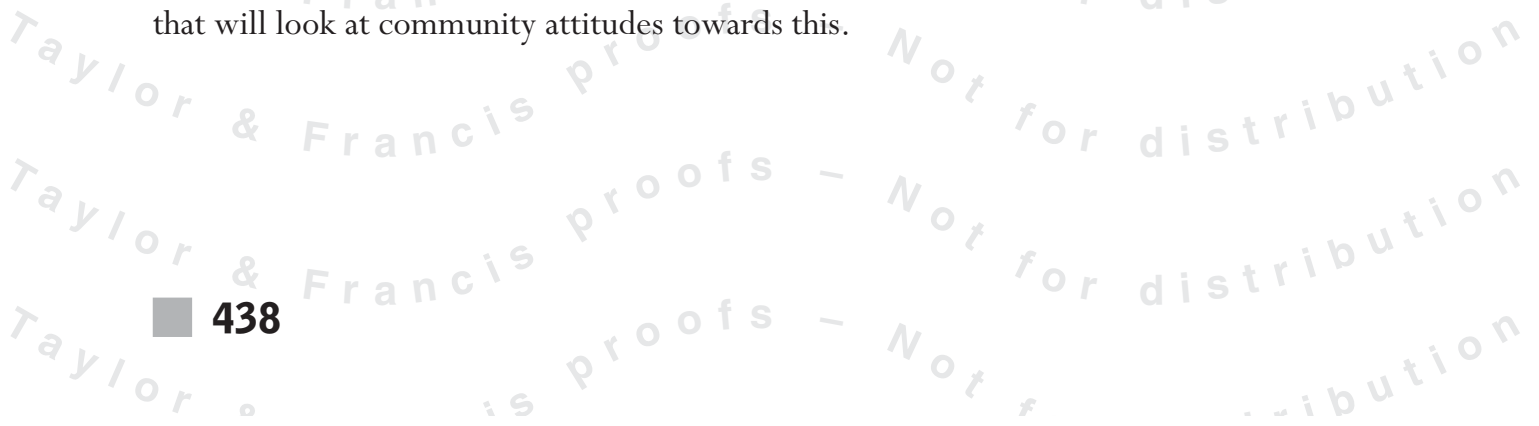




\section{Reviewing the literature}

In qualitative research the literature tends to play a minor role in suggesting a specific research question, but does justify the importance of studying the research problem. This is because qualitative research relies on the views of participants in the study and less upon the direction in the literature identified by the researcher. There are many issues that may be of interest to researchers and practitioners that may be far too current to have attracted much previous research.

\section{Specifying a purpose for the research}

In qualitative research the purpose statement and research questions tend to be general and broad and seek to understand the participants' experiences. The purpose will be more open ended than in quantitative research.

\section{Collecting data}

In qualitative research the data collection tends to consist of using forms with general, emerging questions to permit the participant to generate responses. Data collection may be in the form of text (words) or images (film, photos etc.), and will generally involve collecting this information from a small number of individuals and sites. The aim is to learn from the participants in the study, and to develop forms (protocols) for recoding data as the study proceeds. Often the questions used will change and emerge during data collection as the information is collected from participants. The researcher may also record their own observations of the participants, which may involve recording notes about their behaviour.

\section{Analysing and interpreting data}

In qualitative research the data analysis tends to consist of text analysis, involve developing a description and themes, and tends to consist of stating the larger meaning of the findings. When analysing text, the researcher may gather a text database so that an analysis of groups of sentences or words (text segments) can be made.

\section{Reporting and evaluating research}

In qualitative research the reports tend to use a flexible structure and evaluative criteria, and the researcher tends to take a subjective approach, or at least states any biases they may have.

\section{Mixed methods approach to sport management research}

Edwards and Skinner (2009) discuss how, for a true mixed methods approach, qualitative and quantitative methods have to be combined. If qualitative and quantitative methods are combined effectively to answer a specific research question then one of the following outcomes may arise:

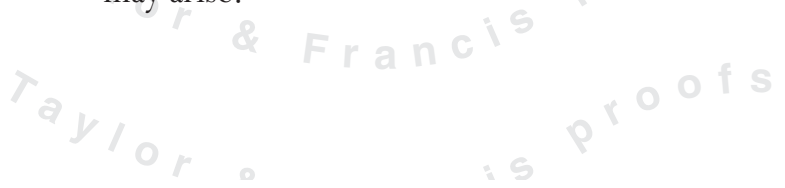


1 Qualitative and quantitative results may 'converge'.

2 Qualitative and quantitative results may relate to different objects or phenomena, but may be 'complementary' to each other and thus can be used to 'supplement' each other.

3 Qualitative and quantitative results may be 'divergent' or 'contradictory'. (p. 6)

Further, Edwards and Skinner (2009) believe that using more than one method to study the same phenomenon in sport management research 'has the potential to strengthen the validity of the results' (p. 7). A typical mixed methods approach may be to start out with a qualitative segment such as an interview, which could then be followed by a quantitative structured interview to clarify some of the survey findings. A mixed methods approach may also lead sport management researchers to modify or expand the research design and/or the data collection methods.

\section{RESEARCH DESIGN}

Research designs are the specific procedures involved in the last three steps of the research process: data collection, data analysis, and report writing. These research designs will differ depending on whether quantitative, qualitative, or mixed methods of research are utilized.

\section{Quantitative research designs}

Creswell (2008) identifies three main types of quantitative research design: experimental, correlational, and survey.

Experimental designs - where the researcher determines whether an activity or materials make a difference in results for participants. This is done by giving one group a set of activities (the intervention) and withholding the set from another group.

Correlational designs - are procedures in which researchers 'measure the degree of association (or relation) between two or more variables using the statistical procedure of correlational analysis. The degree of association, expressed as a number, indicates whether the two variables are related or whether one can predict another' (Creswell, 2008, p. 60). To accomplish this, the researcher 'studies a single group of individuals rather than two or more groups as in an experiment' (p. 60).

Survey designs - 'these seek to describe trends in a large population of individuals. In this case, a survey is a good procedure to use. Survey designs are procedures in which one administers a survey or questionnaire to a small group of people (called the sample group) to identify trends in attitudes, opinions, behaviours, or characteristics of a large group of people (the population)' (Creswell, 2008, p. 61).

\section{Qualitative research designs}

There are a number of research designs in qualitative methods including ethnography, ethnomethodology, narrative inquiry, grounded theory, and a range of emerging ethnographies 
including netnography, ethnodrama, and phenomenography. We will now examine a few of the more commonly used designs briefly.

Ethnography - relates to social research in which the behaviours of participants are studied in their everyday context, rather than under experimental or laboratory conditions. Observation and interviews are the primary methods of data collection, and the data is collected in an 'unstructured' manner, meaning that it is collected in its raw form. In general, the researcher will focus on a single setting or group, and the data analysis will involve the interpretation of the meanings and functions of human actions and is primarily conducted in the form of verbal descriptions and explanations (Hammersley, 1990, p. 1).

Grounded theory - aids the researcher seeking to study social phenomena in its natural setting. For the sport management researcher, this could be a study of athletes at a competition, specific consumers attending a sporting event, or even the management team within a sporting organization. The researcher will engage in a data collection process of field observation, in-depth interviews, and document analysis (Glaser \& Strauss, 1967). Following analysis of one set of data, the researcher then decides what data to collect next and where to find them from other participants, sites, and/or events or incidents. Therefore, the grounded theory researcher develops the theory as it emerges in this ongoing process - referred to by Glaser and Strauss (1967) as 'grounding' the theory in the data. Because of the continual 'grounding' process, the theory accurately reflects the data.

\section{Mixed methods designs}

With the mixed methods approach, the sport management researcher decides to collect both quantitative data (quantifiable data) as well as qualitative data (images, interviews, stories). This is not merely a process of collecting two distinct types of data - quantitative and qualitative. The researcher needs to merge, integrate, link, or embed both strands.

One form of mixed methods design that can be successfully utilized by the sport management researcher is triangulation mixed methods.

In a triangulation study the researcher gathers both quantitative and qualitative data, analyses both datasets separately, compares the results from the analysis of both datasets, and makes an interpretation as to whether the results support or contradict each other. The direct comparison of the two datasets by the researcher provides a 'triangulation' of data sources.

The strength of this design is that it combines the advantages of each form of data - that is, quantitative data provides for generalizability whereas the qualitative data offers information about the context or setting. This design enables a researcher to gather information that uses the best features of both quantitative and qualitative data collection. It can be difficult, however, to transform one form of data into the other form in order to integrate and compare data. Additionally, even if integration of the data is possible, inconsistent results may emerge, making it necessary to collect additional data or revisit the collected databases to reconcile the differences.

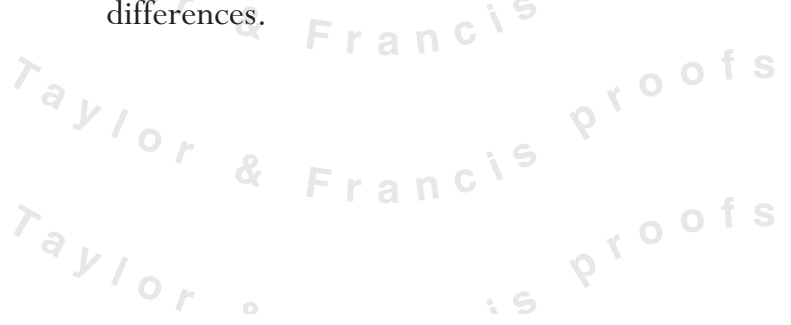




\section{WRITING THE RESEARCH REPORT}

Once one has completed one's research, the next step is to write up the research report. Different mediums will require different formats in a research report, so the steps that follow are a general guide. It is important, however, that the report be constructed in a systematic way and address all aspects of the work carried out and offer an appropriate selection from the findings. By adopting a systematic approach to constructing the research report, the sport management researcher will produce a cohesive and well-defined report.

\section{Introduction}

This is the first section of the research report and outlines the research project - why it was done and how it relates to other research in this same area.

\section{Aims of the research}

This is where the researcher outlines what the aims were, and what they hoped to have achieved. It also describes how the research is significant and whether it addresses an important problem. At the end of the report the researcher should be able to look back at the aims of the research project and reflect on whether or not these aims were achieved and whether they lead to future research.

\section{Literature review}

In this section the researcher will outline how they searched the literature for relevant and key research reports as well as providing details of relevant literature that relates to the current research question. A thorough review of the literature can aid in the development of the research question and the scope and direction of the current research by enabling the sport management researcher to find gaps in the current literature and research questions that need to be addressed.

\section{Sample}

If sampling has been used during data collection, the sport management researcher needs to let the reader know the size and type of sample used.

\section{Questions guiding the investigation}

How were the specific research purposes and aims adapted into the research questions? Good research questions are clear and concise, informed by a review of the literature, motivating and meaningful, significant, and probably most importantly they are questions that need to be answered. 


\section{Data collection methods}

In this section the sport management researcher will discuss how they have approached the collection of data. If the researcher has used qualitative research methods then the specific data collection methodology related to the theoretical framework needs to be outlined here. The sport management researcher then needs to report on exactly what they did and how they went about doing it.

\section{Data analysis methods}

Here the sport management researcher will describe the data analysis methods used.

\section{Findings or results}

In a quantitative study this section will normally appear under the sub-heading 'results' and in a qualitative study it will usually be under 'findings'.

\section{Discussion}

In this section the sport management researcher will aim to present the findings in a factual way and then offer a discussion that stays within the parameters of the data.

\section{Conclusions}

Here the researcher both summarizes their findings and suggests applications of these findings. The researcher may choose to be critical of their findings or the process undertaken, and can look to further research possibilities as a result of this particular study.

\section{References}

All references used in the text need to be included in this section.

\section{Appendices}

Information that is not essential to explain the findings, but that supports the conclusions, should be placed in an appendix.

\section{Abstract}

Whilst this is the final part of the writing process, the abstract will actually appear at the front of the paper. A good abstract should include details of the background to the study, the aims, samples, data collection and analysis methods, and a summary of the findings. 


\section{SUMMARY}

This chapter has provided an introduction to the sport management research process for the budding sport management researcher. The field of sport management research is diverse, complex, and constantly evolving. The last two decades have seen a dramatic change in the research landscape with diverse and emerging methodologies that challenge the existing and sometimes conservative approaches to conducting research. These emerging methodologies can provide sport management researchers with new and exciting ways to conduct, analyse, and report their research findings. However the sport management researcher chooses to approach their research study, the basic premise remains the same - which is that the sport management researcher is seeking to answer important questions and investigate issues of relevance to both the researcher and the sport management practitioner in order to provide potential solutions to emerging problems in the world of sport management research.

\section{REVIEW QUESTIONS}

1. Why is sport management research important? Justify your response with reference to the literature.

2 What are the key differences between qualitative, quantitative, and mixed methods approaches to sport management?

3 Outline the basic research process and apply it to a specific research problem such as community attitudes to the use of illicit drugs in sport.

\section{FURTHER READING}

Amis, J. \& Silk, M. (2005). Rupture: promoting critical and innovative approaches to the study of sport management. Journal of Sport Management, 19, 355-366.

Edwards, A. \& Skinner, J. (2009). Qualitative Research Methods in Sport Management. Oxford: Butterworth-Heinemann/Elsevier.

Edwards, A., Gilbert, K., \& Skinner, J. (2002). Extending the Boundaries: Theoretical Frameworks for Research in Sports Management. Melbourne: Commonground.

Frisby, W. (2005). The good, the bad, and the ugly: critical sport management research. Journal of Sport Management, 19, 1-12.

Gratton, C. \& Jones, I. (2004). Research Methods for Sport Studies. Oxon: Routledge.

Skinner, J. \& Edwards, A. (2005). Inventive pathways: fresh visions of sport management research. Journal of Sport Management, 19,404-421.

\section{WEBSITES}

Asian Association for Sport Management (AASM) http: / / aasm.tw

\section{4}


European Association for Sport Management (EASM) http://www. easm.net

North American Society for Sport Management (NASSM)

http:/ /www.nassm.com

Sport Management Association of Australia \& New Zealand (SMAANZ)

http: / / smaanz.cadability.com.au

\section{REFERENCES}

Amis, J. \& Silk, M. (2005). Rupture: promoting critical and innovative approaches to the study of sport management. Journal of Sport Management, 19, 355-366.

Chalip, L. (2006). Toward a distinctive sport management discipline. Journal of Sport Management, $20,1-21$.

Costa, C. A. (2005). The status and future of sport management: a Delphi study. Journal of Sport Management, 19, 117-142.

Creswell, J. W. (2008). Educational Research (3rded.). Upper Saddle River, NJ: Pearson.

Cunningham, G. B. \& Mahoney, K. (2004). Self-efficacy of part-time employees in university athletics: the influence of organizational commitment, valence of training, and training motivation. Journal of Sport Management, 18, 59-73.

Cuskelly, B. \& Boag, A. (2001). Organisational commitment as a predictor of committee member turnover among volunteer sport administrators: results of a time-lagged study. Journal of Sport Management, 4, 65-88.

Edwards, A. \& Skinner, J. (2009). Qualitative Research in Sport Management. Oxford: Elsevier.

Fink, J. S., Pastore, D. L., \& Riemer, H. (2003). Managing employee diversity: perceived practices and organizational outcomes in NCAA division III athletic departments. Sport Management Review, 6, 147-168.

Frisby, W. (2005). The good, the bad, and the ugly: critical sport management research. Journal of Sport Management, 19, 1-12.

Glaser, B. \& Strauss, A. (1967). The Discovery of Grounded Theory: Strategies for Qualitative Research. New York: Aldine.

Hammersley, M. (1990). Reading Ethnographic Research. London: Longman.

Murray, D. \& Howat, G. (2002). The relationships among service quality, value, satisfaction, and future intentions of customers at an Australian sports and leisure centre. Sport Management Review, 5, 25-43.

Pitts, B. G. (2001). Sport management at the millennium: a defining moment. Journal of Sport Management, 15, 1-9.

Quatman, C. (2006). The Social Construction of Knowledge in the Field of Sport Management: A Social Network Perspective. Unpublished doctoral dissertation, The Ohio State University, Columbus.

Shilbury, D. (2001). Examining board member roles, functions and influence: a study of Victorian sporting organisations. International Journal of Sport Management, 2, 253-281.

Skinner, J. \& Edwards, A. (2005). Inventive pathways: fresh visions of sport management research. Journal of Sport Management, 19, 404-421.

Thomas, J. R., Nelson, J. K., \& Silverman, S. J. (2005). Research Methods in Physical Activity (5th ed.). Champaign, IL: Human Kinetics. 